\title{
Treatment and Prophylaxis of Post-pericardiotomy Syndrome in Cardiac Surgery Patients: A Meta-analysis of Main Trials
}

\section{Omar Giacinto}

Campus Bio-Medico University: Universita Campus Bio-Medico di Roma

Alessandro Minati

Umberto I Policlinico di Roma

Mario Lusini

Campus Bio-Medico University Hospital: Policlinico Universitario Campus Bio-Medico

Francesco Cardetta

Campus Bio-Medico University Hospital: Policlinico Universitario Campus Bio-Medico

Sara Saltarocchi ( $\sim$ sara.saltarocchi@uniroma1.it)

Umberto I Policlinico di Roma https://orcid.org/0000-0002-5052-1205

Mizar D'Abramo

Umberto I Policlinico di Roma

Fabio Miraldi

Umberto I Policlinico di Roma

Massimo Chello

Campus Bio-Medico University Hospital: Policlinico Universitario Campus Bio-Medico

\section{Research Article}

Keywords: Post-pericardiotomy syndrome, Colchicine, Indomethacin, Dexamethasone

Posted Date: June 18th, 2021

DOI: https://doi.org/10.21203/rs.3.rs-610479/v1

License: @) (7) This work is licensed under a Creative Commons Attribution 4.0 International License. Read Full License 


\section{Abstract}

Purpose: Post-pericardiotomy syndrome (PPS) is a common complication of cardiac surgery. This study represents a meta-analysis of trials on treatment and prophylaxis of PPS with colchicine, indomethacin and dexamethasone. The primary endpoint was to investigate the efficacy of these drugs, while the secondary endpoints were the efficacy in reducing hospital readmission, cardiac tamponade, symptom persistence, atrial fibrillation as well as their safety and adverse effects.

Methods: Literature research was carried out using PubMed. Inclusion criteria were: studies investigating $\geq 10$ patients with clinically PPS in which colchicine, dexamethasone and indomethacin were compared with placebo. We excluded publications referring only to animal experiments or in vitro experiments, studies on $<10$ patients, case reports, congress reports, review articles, editorial letters.

Results: Among studies with post-operative colchicine treatment, two of them demonstrated a significant reduction of PPS [95\% $\mathrm{Cl}-0,86(-1,96,0,25)]$, [95\% $\mathrm{Cl}$ $0,24(0,03,0,44)]$. In the single pre-surgery colchicine administration study, a reduction of PPS was obtained $[95 \% \mathrm{Cl}-0,55(-1,04,-0,06)]$. In the indomethacin study, pre-surgery administration was linked to a reduction of PPS $[95 \% \mathrm{Cl}-2,18(-4,31,-0,06)]$. This result was not reported with pre-operative dexamethasone intake $[95 \% \mathrm{Cl} 0,50(0,12,0,88)]$.

Conclusion: The overall results show a better outcome when colchicine and indomethacin were administered as primary prophylactic agents in order to prevent PPS and PE. Further studies are needed to confirm these results.

\section{Introduction}

Post-pericardiotomy syndrome (PPS) is a common complication affecting the pericardium and pleurae following cardiac surgery, associated with significant morbidity and prolonged inhospital stay. Although the pathophysiology remains unclear, surgical trauma and cardiopulmonary bypass (CPB) are thought to play an important role by triggering a systemic inflammatory response syndrome (SIRS) [1]. For this reason, nonsteroidal antiinflammatory drugs (NSAIDs), steroids and colchicine are the main pharmacological agents used to treat this condition, despite their side effects. Currently, there is no scientific evidence of resolution or prevention of this condition with a specific drug.

PPS has a variable clinical presentation and is defined by at least 2 of the following 5 signs and symptoms: new-onset pericardial effusion, new-onset pleural effusion, fever, pleuritic chest pain, and pericardial or pleural rubbing on physical examination [2]. Due to the similarities in their anatomical features and the relationship of the structures, we should also consider a similar etiopathogenesis for both pleural and pericardial effusions. This also reflects on the surgical technique, which often involves both structures: after incising the pericardium, the pleurae could be opened and drainage tubes positioned.

Pleuro-pericardial effusion may be detected starting a few days after surgery until the follow-up period, often complicating the post-operative course. In most cases, the accumulated fluid may cause respiratory distress (atelectasis) and infections, leading to a prolonged hospital stay or intensive care unit (ICU) admission.

Diagnosis of pericardial effusion relies on postoperative echocardiography, while pleural effusion (PE) is usually diagnosed through chest x-ray. A radiological classification of pleural effusion using a semi-quantitative scale has been proposed [3] and is shown in Table 1. Thoracic ultrasound, on the other hand, has the advantage of being less invasive, readily available and repeatable. Furthermore, chest ultrasonography has more sensibility and reliability than radiography $[4,5]$. Also in this case, a classification is used to assess the amount of pleural effusion [6] (Table 2).

Pericardiocentesis is performed when the increased pressure in the pericardial cavity leads to echocardiographic signs of cardiac chambers compression (right and left atrial collapse, ventricular collapse, swinging heart etc.) and subsequent haemodynamic instability.

The best management of pleural effusion is controversial. Clear indications on the right timing to perform a thoracentesis are lacking. Usually, a pleural effusion is considered complicated when thoracentesis is needed and is accompanied by clinical and Arterial Blood Gas (ABG) parameters alterations. Nonsteroidal anti-inflammatory drugs, colchicine and steroids can be employed. Thoracentesis is typically performed as a final resort, considering that this procedure is not free from complications such as haemorrhage and pneumothorax.

In order to attenuate the inflammatory response, a single dose of long-acting corticosteroids is given during heart surgery in many European countries, although definitive results of its efficacy are lacking [7]. The DECS study published by Bunge J.J.H et al. [3] is the largest one among those on corticosteroids usage. It is a multicenter randomized trial that compares the use of dexamethasone with placebo in primary prophylaxis of PPS, giving to selected patients 1 $\mathrm{mg} / \mathrm{kg}$ of dexamethasone at the beginning of the anesthetic procedures. Statistical evaluation testified that there were no differences between the two groups.

Colchicine and Indomethacin can be also employed in primary prophylaxis of PPS. Several randomized controlled trials (RCT) were published, especially on colchicine. In our study we combined Finkelstein Y et al. study [8], COPPS study [9], COPPS-2 study [10], POPE study [11] and Izadi AA et al. [12] for evaluating colchicine efficacy. Regarding indomethacin, we investigated the work of Inan MB et al. [13].

\section{Methods}

Literature research was carried out using PubMed. We combined the following key words to identify the publications in the following query: "pericarditis OR pericardial effusion OR pleuro-pericardial syndrome AND colchicine OR dexamethasone OR indomethacine AND heart surgery". We applied the following inclusion criteria: studies on $\geq 10$ patients with clinical pericarditis or post-pericardiotomy syndrome in which colchicine, dexamethasone and indomethacin 
were compared with placebo. We excluded publications referring only to animal experiments or in vitro experiments, human studies on < 10 patients, case reports, congress reports, review articles, editorial letters. The full publications that met the criteria listed before were included in the analysis.

The primary end-point of the study was to investigate the efficacy of colchicine, dexamethasone and indomethacin in the treatment and prevention of PPS and pleural effusion. The secondary end-points were to assess the efficacy of the three drugs in reducing hospital readmission, cardiac tamponade, symptom persistence, atrial fibrillation after $72 \mathrm{~h}$, as well as the safety and adverse effects of pharmacological treatment.

We collected data regarding study characteristics, publication year, randomization, blinding, intention-to-treat analysis, patients clinical characteristics, treatment indication and duration, pharmacological dosage, follow-up, clinical outcomes. Clinical features and study methods are summarized in Table 3.

The assessment of study quality was obtained by Jadad scale [14] and included randomization, blinding of participants and dropouts. Upon the obtained value, Jadad score allows to establish the probability of bias (Table 4).

\section{Statistical analysis}

Metanalysis was performed by random effect model (Der Simonian - Laird model). We considered risk ratios related to each single study with confidence interval percentage weight on the Overall Risk ratio.

Hypothesis testing for equivalence was set at the two-tailed 0.05 level. Heterogeneity was based on the Cochran Q test, with 12 values.

Funnel plots by graphical inspection and Egger regression test were used for assessment of publication bias.

Univariable meta-regression was performed to explore a significant increase or decrease in the number of patients in the treatment group who had the event. For each group some independent variables were omitted for reasons of lack of data or due to multicollinearity.

\section{Results}

In this review we examined an amount of 361 studies from 1977 to 2016 . Of these studies we considered only 7 randomized controlled trials, including trials regarding PPS and pleural effusion after heart surgery. 5 of them were double blind multicenter randomized trials [8, 9, 10, 11], 1 was a triple blind multicenter randomized trial [12], 1 was a single center randomized trial. Follow up period was from 1 to 12 months. Only five patients got lost during the follow up of all studies. The groups did not differ in clinical characteristics and type of surgery.

The indication for pharmacological therapy was dependent upon PPS and postoperative pericardial effusion.

The seven prospective studies from 2002 to 2015 included 1677 patients (mean age 60,8, male 67,4\%). Control group received placebo. The weight-adjusted colchicine dosage was $0.5 \mathrm{mg}$ in three studies and $1 \mathrm{mg}$ in two studies. The duration of colchicine treatment was between 14 days and 30 days. It was started 48-72 hours before surgery [10], on 3rd postoperative day [8, 9], on day $7,30[11]$ and 3 weeks after heart surgery [12].

Indomethacin dosage was $25 \mathrm{mg} 3$ times/day for 3 days before surgery. Treatment duration lasted for six weeks after operation.

Dexamethasone dosage was $1 \mathrm{mg} / \mathrm{Kg}$ i.v. as a single intraoperative bolus.

\section{Main Outcomes}

Primary endpoints were related to reduction of pericardial and pleural effusion in all the studies examined, while there was no homogeneity with secondary endpoints in the study groups.

In Forest and Funnel plot statistical analysis upon primary endpoints was reported an overall effect size only in two studies (Fig. 1A, Fig. 1B).

Forest and Funnel plot for secondary endpoints demonstrated non significant effect size depending also on the heterogeneity of the pathologies involved (Fig. 2A, Fig. 2B).

Adverse effects contemplated gastrointestinal intolerance (GI), allergic reactions (AR), renal failure (RF), pancreatitis (PR), hepatotoxicity (HT), alopecia (AP), leucopenia (LP). Adverse effects ranged from 7-20\%. Even in Adverse effects forest plot analysis doesn't mean an homogeneity of demographics (Fig. 3).

Finkelstein et al., COPPS 2010 study, Copps 2014 study (all three studies referred to colchicine) and Inan et al. (Indomethacine) reported as results a reduction of PPS and PE, but POPE - 2 2015, Amoli et al. study and Bunge et al. (Dexamethasone) registered no reduction of PPS or PE.

In particular, Finkelstein et al. reported a prospective, randomized, double-blind design in which they demonstrated a better outcome for patients undergoing colchicine treatment $[95 \% \mathrm{Cl}-0,86(-1,96,0,25)]$.

COOPS study reported a significant reduction of the incidence of the PPS at 12 months compared with placebo $[95 \% \mathrm{Cl}-1,01(-1.635,-0.383)]$ and the secondary endpoint including hospitalization, cardiac tamponade, constrictive pericarditis, and relapses at $18 \mathrm{months}[95 \% \mathrm{Cl}-0,04(-0,25,0,17)]$. The rates of side effects and drug withdrawal were similar in the colchicine and placebo groups although colchicine showed a trend towards an increased rate of both events. No severe side effects were recorded $[95 \% \mathrm{Cl} \mathrm{0,24}(0,03,0,44)]$. 
In COOPS-2 trial a significant reduction of incidence of PPS was reported $[95 \% \mathrm{Cl}-0,55(-1,04,-0,06)]$. As secondary endpoints only incidence of atrial fibrillation was sensibly reduced compared with the control group. No significant differences were recorded between the two groups [ $95 \% \mathrm{Cl}-0,04$ ( $-0,25$, $0,17)]$. Adverse effects were more common in the Colchicine group, especially due to gastrointestinal events $[95 \% \mathrm{Cl} 0,13(-0,08,0,34)]$.

In POPE- 2 investigation there was no difference between Colchicine group and control group [ $95 \% \mathrm{Cl}-0,38(-1,00,0,24)]$ for the incidence of PPS. Secondary endpoints were similar in two groups [ $95 \% \mathrm{Cl} 0,09(-0,19,0,37)]$.

In Amoli et al. trial no differences between the study groups were registered as primary endpoints $[95 \% \mathrm{Cl} 0,36(-0,30,1,02)]$ and secondary endpoints $[95 \% \mathrm{Cl}$ $0,02(-0,30,0,34)]$.

Inan et al. explored indomethacin effect on pericardial effusion when administered 7 days before surgery. Medication continued for six weeks after operation. We quote this study for its statistical features similar to the other in this review, but its low number of patients is a limit for a statistical comparison with other studies with a high number of patients enrolled. It is worth mentioning that during hospitalization and follow-up a significant positive difference was registered between the Indomethacin group and control group.

Bunge et al. trial compared $1 \mathrm{mg} / \mathrm{kg}$ single dose intraoperative dexamethasone with placebo group. No significant statistical data was recorded for primary prophylaxis on PPS $[95 \% \mathrm{Cl} 0,50(0,12,0,88)]$. Also for secondary endpoints there was no statistical significance $[95 \% \mathrm{Cl}-0,03(-0,18,0,12)]$.

Finkelstein et al., COPPS 2010 study, Copps 2014 study (all three studies referred to colchicine) and Inan et al. (Indomethacin) reported as results a reduction of PPS and PE, but POPE - 2 2015, Amoli et al. study and Bunge et al. (Dexamethasone) registered no reduction of PPS or PE.

In Table 5 are reported characteristics of population study in order to potentially explore factors reducing or increasing the number of events. The analysis failed to show any significant triggering factor.

Instead, pre-operative pericardial effusion was identified as a factor able to impact on studies outcome. Indeed, in Table 6, between the different characteristics analyzed and reported, none of the other factors, despite pre-operative PE, have achieved an association with the heterogeneity between studies.

\section{Discussion}

An incidence of $1-6 \%$ of PPS and PE is recorded in cardiac surgery $[15,16,17,18]$. Aortic root surgery is associated with an increase in effusion to $31,6 \%[19]$.

There are several factors that may cause a PPS in response to cardiac surgery. Cardio-pulmonary by-pass (CPB) plays a major role due to the inflammatory activation process. Prolonged time of CPB may enhance the inflammatory response. Surgical trauma may cause an autoimmune-based inflammatory syndrome $[20,21]$. Duration of the operation is also considered a determinant part of the inflammatory response. The association between the levels of circulating cytokines and incidence of PPS has been evaluated in patients who underwent coronary artery bypass grafting (CABG). A low preoperative IL-8 level was identified as a high risk marker for development of PPS. It is thought that IL-8 may have a protective effect on endothelial and mesothelial cells and therefore patients with high preoperative levels of IL-8 may be less prone to PPS. The limited number of studies that have evaluated particular serum biomarkers and histological markers underlines the need for a more systematic examination on cellular and genomic expression of plasmatic factors which confer an increased susceptibility to PPS.

PE may be localized in the entire pericardial space but regional effusions may be detected.

The Post-pericardiotomy syndrome may occur days or months after surgery. Generally it occurs with nonspecific signs and symptoms, such as fever and exhaustion, but it may also present with chest pain and breathing difficulties. Symptomatology depends on the inflammatory reaction triggered after surgical trauma.

Complications related to PPS after heart surgery may cause slow recovery and prolonged hospitalization.

Among PPS complications, pleural effusion can cause dyspnea, peripheral desaturation up to a real respiratory fatigue. Pericardial effusion is another relevant complication, which can lead to chest pain, asthenia, until the onset of cardiac arrhythmias or cardiac tamponade. These complications may lead to greater morbidity as well as to a greater risk of mortality and a progressive delay in the rehabilitation process and reintegration to normal life.

This syndrome presents with pleural or pericardial reaction, characterized by fever, chest pain, and a friction rub. Although symptoms often are specific to PPS, diagnosis may be aided by the use of radiography, echocardiography, electrocardiography, and laboratory analysis. Chest radiology can highlight the presence of pleural effusion (Table 1) whose degree may indicate a possible treatment. In addition to radiological evaluation, pleural ultrasound has a great specificity in diagnosing a pleural effusion (Table 2). Pericardial effusion is instead evaluated by echocardiography, highlighting both the effusion rate and any interaction with cardiac contractility.

Several studies reported various treatments, in particular with non-steroidal anti-inflammatory drugs, colchicine and corticosteroids. These drugs are especially used for PPS and PE treatment. Only few studies are reported for primary prophylaxis of PPS.

In this review we investigated 7 randomized trials on colchicine, indomethacin and dexamethasone used for primary prophylaxis purposes. All trials have an homogenous number of enrolled patients, except the work on indomethacin with a lower number of patients in comparison to the other studies. This 
represents a bias on statistical analysis. We quote this work since it is the only one regarding indomethacin to have a similar feature to the other ones we have studied.

The first 5 studies reported in this review concerned colchicine treatment in cardiac surgery patients.

Finkelstein et al. [8] performed a prospective, randomized double blind study. They found a statistical significance in their data concerning the colchicine treatment group. No significant data were reported on specific secondary end points and adverse effects.

Imazio et al (COPPS - 2)[10] attested in their multicenter study that preoperative administration of colchicine significantly reduced postoperative inflammation and its complication, especially PPS. As suggested by a subgroup analysis, colchicine was more efficacious against C-reactive protein elevation. They avoided a loading dose and used weight-adjusted doses in order to obtain a higher degree of treatment adherence. High rates of adverse events were registered such as gastrointestinal intolerance and drug discontinuation. These findings suggested that colchicine must be employed only in well selected patients.

Meurin et al (POPE-2 study) [11], assessing the effectiveness of colchicine to treat asymptomatic postoperative pericardial effusion, found that the use of the drug did not significantly reduce the volume of PE. Authors justified the absence of efficacy considering the inflammatory etiology not being the main trigger of $\mathrm{PE}$, considering more plausible etiologies postoperative hemorrhagic effusion and PE secondary to heart failure. They concluded that in patients with a true PPS colchicine may be efficacious as described in the ICAP study [22].

Izadi Amoli et al. performed a triple blind trial comparing 2 weeks treatment group with placebo group. Authors found that there was no difference in the two groups regarding postoperative mild to moderate PE. It was a study conducted in a high turnover specialized department with various cardiac pathologies. According to randomization rules there were no significant differences between the 2 study groups in baseline and clinical characteristics. Forest plot, used in this analysis, confirmed the main findings related to the no significance of colchicine use on reducing PE compared with placebo group.

Inan et al.[13] investigated the prophylactic indomethacin effect on postoperative PE. Within the limitations of the low number of enrolled patients, results of this study suggest that preoperative indomethacin intake may have a beneficial role on the outcome and incidence of postoperative PE. Conclusions of the authors indicated indomethacin an alternative protocol to other drugs to avoid postoperative PE.

Bunge et al.[3] found no protective effect of a single high intraoperative dose of dexamethasone on PPS or complicated PPS in a cohort of patients undergoing valvular surgery.

\section{Conclusion}

PPS and PE are the epiphenomena of the inflammatory status secondary to heart surgery, especially when CPB is adopted. Review of the main studies about PPS and PE treatment on cardiac surgery represents a main concern in avoiding complications such as cardiac tamponade or infections in the first postoperative days.

Limits of this study may be found in the heterogeneity of the population and in the timing of drug administration. In the studies with postoperative colchicine administration, 2 of them demonstrated a significant reduction of PE. In the single pre-surgery colchicine administration study, a reduction of PE was as well obtained. In the indomethacin study, pre-surgery administration was linked to a reduction of PE. This result was not reported with pre-operatively dexamethasone intake. The aforementioned studies also demonstrated no reduction in PE of non-inflammatory etiology. In future studies it could be useful that this feature is excluded from primary endpoints.

The overall results show a better outcome in cases in which colchicine and indomethacin were administered as primary prophylactic agents in order to prevent PPS and PE. Given their low adverse effects rates, clinical administration of colchicine and indomethacin in the preoperative setting should be given better consideration and this should be the aim of future investigations.

\section{Declarations}

\section{Author Declarations}

Ethics approval and consent to participate: See "Compliance with Ethical Standards" section below.

Consent for publication: See "Compliance with Ethical Standards" section below.

Availability of data and materials: The data that support the findings of this study are openly available on PubMed at https://doi.org/10.1007/s00059-002-

2376-5; https://doi.org/10.1093/eurheartj/ehq319; https://doi.org/10.1001/jama.2014.11026;_https://doi.org/10.1016/j.jacc.2015.05.078;

https://doi.org/10.1016/j.ahj.2015.09.020; https://doi.org/10.1016/j.jtcvs.2010.03.021; https://doi.org/10.1016/j.ahj.2014.03.017

Code availability: Not applicable.

Conflicts of interest/Competing interests: All authors certify that they have no affiliations with or involvement in any organization or entity with any financial interest or non-financial interest in the subject matter or materials discussed in this manuscript.

Funding: The authors received no financial support for the research, authorship and/or publication of this article.

Authors' contributions: See the appropriate section on the title page. 
Acknowledgments: Not applicable.

\section{Compliance with Ethical Standards}

Disclosure of potential conflicts of interest: The authors declare that they have no conflict of interest.

Research involving Human Participants and/or Animals: This manuscript is a metanalysis of previously published studies. Policlinico Umberto I and Campus Biomedico Ethics Committees have confirmed that no ethical approval is required.

Consent to participate: Informed Consent was obtained from all participants included in the studies.

Consent to publish: Participants have consented to the submission of the study to the journal.

\section{References}

1. Wan S, LeClerc JL, Vincent JL. Inflammatory response to cardiopulmonary bypass: mechanisms involved and possible therapeutic strategies. Chest. 1997 Sep;112(3):676-92. doi: 10.1378/chest.112.3.676. PMID: 9315800.

2. Imazio M, Brucato A, Ferrazzi P, Spodick DH, Adler Y. Postpericardiotomy syndrome: a proposal for diagnostic criteria. J Cardiovasc Med (Hagerstown). 2013 May;14(5):351-3. doi: 10.2459/JCM.0b013e328353807d. PMID: 22526225.

3. Bunge JJ, van Osch D, Dieleman JM, Jacob KA, Kluin J, van Dijk D, Nathoe HM; Dexamethasone for Cardiac Surgery (DECS) Study Group. Dexamethasone for the prevention of postpericardiotomy syndrome: A DExamethasone for Cardiac Surgery substudy. Am Heart J. 2014 Jul;168(1):12631.e1. doi: 10.1016/j.ahj.2014.03.017. Epub 2014 Apr 5. PMID: 24952869.

4. Eibenberger KL, Dock WI, Ammann ME, Dorffner R, Hörmann MF, Grabenwöger F. Quantification of pleural effusions: sonography versus radiography. Radiology. 1994 Jun;191(3):681-4. doi: 10.1148/radiology.191.3.8184046. PMID: 8184046.

5. Azoulay E. Pleural effusions in the intensive care unit. Curr Opin Pulm Med. 2003 Jul;9(4):291-7. doi: 10.1097/00063198-200307000-00008. PMID: 12806242.:291-297

6. Lindner M, Thomas R, Claggett B, Lewis EF, Groarke J, Merz AA, Silverman MB, Swamy V, Rivero J, Hohenstein C, Solomon SD, McMurray JJ, Steigner ML, Platz E. Quantification of pleural effusions on thoracic ultrasound in acute heart failure. Eur Heart J Acute Cardiovasc Care. 2020 Aug;9(5):513-521. doi: 10.1177/2048872620901835. Epub 2020 Jan 24. PMID: 31976745; PMCID: PMC7644143.

7. Dieleman JM, van Paassen J, van Dijk D, Arbous MS, Kalkman CJ, Vandenbroucke JP, van der Heijden GJ, Dekkers OM. Prophylactic corticosteroids for cardiopulmonary bypass in adults. Cochrane Database Syst Rev. 2011 May 11;(5):CD005566. doi: 10.1002/14651858.CD005566.pub3. PMID: 21563145.

8. Finkelstein Y, Shemesh J, Mahlab K, Abramov D, Bar-El Y, Sagie A, Sharoni E, Sahar G, Smolinsky AK, Schechter T, Vidne BA, Adler Y. Colchicine for the prevention of postpericardiotomy syndrome. Herz. 2002 Dec;27(8):791-4. doi: 10.1007/s00059-002-2376-5. PMID: 12574898.

9. Imazio M, Trinchero R, Brucato A, Rovere ME, Gandino A, Cemin R, Ferrua S, Maestroni S, Zingarelli E, Barosi A, Simon C, Sansone F, Patrini D, Vitali E, Ferrazzi P, Spodick DH, Adler Y; COPPS Investigators. COlchicine for the Prevention of the Post-pericardiotomy Syndrome (COPPS): a multicentre, randomized, double-blind, placebo-controlled trial. Eur Heart J. 2010 Nov;31(22):2749-54. doi: 10.1093/eurheartj/ehq319. Epub 2010 Aug 30. PMID: 20805112

10. Imazio M, Brucato A, Ferrazzi P, Pullara A, Adler Y, Barosi A, Caforio AL, Cemin R, Chirillo F, Comoglio C, Cugola D, Cumetti D, Dyrda O, Ferrua S, Finkelstein Y, Flocco R, Gandino A, Hoit B, Innocente F, Maestroni S, Musumeci F, Oh J, Pergolini A, Polizzi V, Ristic A, Simon C, Spodick DH, Tarzia V, Trimboli S, Valenti A, Belli R, Gaita F; COPPS-2 Investigators. Colchicine for prevention of postpericardiotomy syndrome and postoperative atrial fibrillation: the COPPS-2 randomized clinical trial. JAMA. 2014 Sep 10;312(10):1016-23. doi: 10.1001/jama.2014.11026. PMID: 25172965.

11. Meurin P, Lelay-Kubas S, Pierre B, Pereira H, Pavy B, lliou MC, Bussiere JL, Weber H, Beugin JP, Farrokhi T, Bellemain-Appaix A, Briota L, Tabet JY; French Society of Cardiology. Colchicine for Post-Operative Pericardial Effusion: Preliminary Results of the POPE-2 Study. J Am Coll Cardiol. 2015 Sep 8;66(10):1198-9. doi: 10.1016/j.jacc.2015.05.078. PMID: 26338000.

12. Izadi Amoli A, Bozorgi A, HajHossein Talasaz A, Salehi Omran A, Mortazavi SH, Jalali A, Nasirpour S, Jenab Y. Efficacy of colchicine versus placebo for the treatment of pericardial effusion after open-heart surgery: A randomized, placebo-controlled trial. Am Heart J. 2015 Dec;170(6):1195-201. doi: 10.1016/j.ahj.2015.09.020. Epub 2015 Oct 3. PMID: 26678641.

13. Inan MB, Yazıcıoglu L, Eryılmaz S, Sırlak M, Cetıntas D, Kaya B, Ozyurda U. Effects of prophylactic indomethacin treatment on postoperative pericardial effusion after aortic surgery. J Thorac Cardiovasc Surg. 2011 Feb;141(2):578-82. doi: 10.1016/j.jtcvs.2010.03.021. Epub 2010 Apr 22. PMID: 20416893.

14. Jadad AR, Carroll D, Moore A, McQuay H. Developing a database of published reports of randomised clinical trials in pain research. Pain. 1996 Aug;66(23):239-46. doi: 10.1016/0304-3959(96)03033-3. PMID: 8880846.

15. Eryilmaz S, Emiroglu O, Eyileten Z, Akar R, Yazicioglu L, Tasoz R, Kaya B, Uysalel A, Ucanok K, Corapcioglu T, Ozyurda U. Effect of posterior pericardial drainage on the incidence of pericardial effusion after ascending aortic surgery. J Thorac Cardiovasc Surg. 2006 Jul;132(1):27-31. doi: 10.1016/j.jtcvs.2006.01.049. PMID: 16798298.

16. Ofori-Krakye SK, Tyberg TI, Geha AS, Hammond GL, Cohen LS, Langou RA. Late cardiac tamponade after open heart surgery: incidence, role of anticoagulants in its pathogenesis and its relationship to the postpericardiotomy syndrome. Circulation. 1981 Jun;63(6):1323-8. doi: 10.1161/01.cir.63.6.1323. PMID: 7226478.

17. Kuvin JT, Harati NA, Pandian NG, Bojar RM, Khabbaz KR. Postoperative cardiac tamponade in the modern surgical era. Ann Thorac Surg. 2002 Oct;74(4):1148-53. doi: 10.1016/s0003-4975(02)03837-7. PMID: 12400760. 
18. Stevenson LW, Child JS, Laks H, Kern L. Incidence and significance of early pericardial effusions after cardiac surgery. Am J Cardiol. 1984 Oct 1;54(7):848-51. doi: 10.1016/s0002-9149(84)80219-2. PMID: 6486036.

19. Alkhulaifi AM, Speechly-Dick ME, Swanton RH, Pattison CW, Pugsley WB. The incidence of significant pericardial effusion and tamponade following major aortic root surgery. J Cardiovasc Surg (Torino). 1996 Aug;37(4):385-9. PMID: 8698784.

20. Erlich JF, Paz Z. Postpericardial injury syndrome: an autoimmune phenomenon. Clin Rev Allergy Immunol. 2010 Apr;38(2-3):156-8. doi: 10.1007/s12016009-8147-9. PMID: 19582596.

21. Kim S, Sahn SA. Postcardiac injury syndrome. An immunologic pleural fluid analysis. Chest. 1996 Feb;109(2):570-2. doi: 10.1378/chest.109.2.570. PMID: 8620742.

22. Imazio M, Brucato A, Cemin R, Ferrua S, Maggiolini S, Beqaraj F, Demarie D, Forno D, Ferro S, Maestroni S, Belli R, Trinchero R, Spodick DH, Adler Y; ICAP Investigators. A randomized trial of colchicine for acute pericarditis. N Engl J Med. 2013 Oct 17;369(16):1522-8. doi: 10.1056/NEJMoa1208536. Epub 2013 Aug 31. PMID: 23992557.

\section{Tables}

Table 1

Radiological pleural effusion classification.

\begin{tabular}{|lll|}
\hline Scale & Effusion & Localization \\
\hline 0 & No effusion & \\
\hline 1 & Minor effusion. & not above the highest level of diaphragm. \\
\hline 2 & Moderate effusion. & above the highest level of diaphragm but $<25 \%$ of chest height. \\
3 & Large effusion. & $>25 \%$ of chest height, or need for pleural tap. \\
\hline
\end{tabular}

Table 2

Ecographic pleural effusion (PEF) classification.

\begin{tabular}{|c|c|}
\hline Scale & Effusion \\
\hline 0 & No PEF visible \\
\hline 1 & PEF only visible in the costo-phrenic angle (CPA). \\
\hline 2 & $\begin{array}{l}\text { PEF extends over the CPA without a clear separation of } \\
\text { the lung base from the diaphragm. }\end{array}$ \\
\hline 3 & Clear separation between diaphragm and lung base at any point during the respiratory cycle \\
\hline 4 & $\begin{array}{l}\text { PEF occupies more than } 50 \% \text { of the basal pleural cavity } \\
\text { visible in the standardised imaging plane. }\end{array}$ \\
\hline
\end{tabular}


Table 3

Studies feature.

\begin{tabular}{|c|c|c|c|c|c|c|c|c|c|c|c|c|}
\hline $\mathbf{N}^{\circ}$ & Study/Year & $\begin{array}{l}\text { Design } \\
\text { and } \\
\text { setting }\end{array}$ & $\begin{array}{l}\text { Placebo } \\
\text { and } \\
\text { control }\end{array}$ & Indication & & N.patients & Dose & $\begin{array}{l}\text { Treatment dur } \\
\text { (months) }\end{array}$ & tion & $\begin{array}{l}\text { Outcor } \\
\text { assess }\end{array}$ & Safety & $\begin{array}{l}\text { Follow- } \\
\text { up } \\
\text { (month }\end{array}$ \\
\hline 1 & $\begin{array}{l}\text { Finkelstein } \\
\text { et al. } 2002\end{array}$ & $\begin{array}{l}\text { Multicenter, } \\
\text { randomized, } \\
\text { double blind }\end{array}$ & yes & $\begin{array}{l}\text { PPS } \\
\text { Prevention }\end{array}$ & 111 & $64 \pm 11$ & $\begin{array}{l}\text { On p } \\
\text { mg }\end{array}$ & o. day 30.5 & 1 & & $\begin{array}{l}\text { PPS } 3 \\
\text { months }\end{array}$ & yes \\
\hline 2 & $\begin{array}{l}\text { COPPS } \\
2010\end{array}$ & $\begin{array}{l}\text { Multicenter } \\
\text { randomized, } \\
\text { double blind }\end{array}$ & yes & $\begin{array}{l}\text { PPS } \\
\text { Prevention }\end{array}$ & 360 & $65.7 \pm 12.3$ & $\begin{array}{l}\text { Onp } \\
\text { follo } \\
\text { twic }\end{array}$ & $\begin{array}{l}\text { o. day } 31 \mathrm{mg} \\
\text { ved by } 0.5 \mathrm{mg} \\
\text { daily }\end{array}$ & 1 & & $\begin{array}{l}\text { PPS } 12 \\
\text { months }\end{array}$ & yes \\
\hline 3 & $\begin{array}{l}\text { COPPS2 } \\
2014\end{array}$ & $\begin{array}{l}\text { Multicenter } \\
\text { randomized, } \\
\text { double blind }\end{array}$ & yes & $\begin{array}{l}\text { PPS } \\
\text { Prevention }\end{array}$ & 360 & $67.5 \pm 10.5$ & $\begin{array}{l}\text { Star } \\
\text { prior } \\
\text { once } \\
\text { acco } \\
\text { weig }\end{array}$ & $\begin{array}{l}\text { ng } 48 \text { to } 72 \mathrm{~h} \\
\text { surgery } 0.5 \mathrm{mg} \\
\text { /twice daily } \\
\text { ding to patient } \\
\text { th }\end{array}$ & 1 & & $\begin{array}{l}\text { PPS } 3 \\
\text { months }\end{array}$ & yes \\
\hline 4 & $\begin{array}{l}\text { POPE - } 2 \\
2015\end{array}$ & $\begin{array}{l}\text { Multicenter } \\
\text { randomized, } \\
\text { double blind }\end{array}$ & & $\begin{array}{l}\text { PE post } \\
\text { heart } \\
\text { Surgery }\end{array}$ & 197 & 64.5 & $\begin{array}{l}1 \mathrm{~ms} \\
\text { days }\end{array}$ & /day for 14 & 0.5 & & PPS 14 days & yes \\
\hline 5 & $\begin{array}{l}\text { Izadi } \\
\text { Amoli A. et } \\
\text { al. } 2015\end{array}$ & $\begin{array}{l}\text { Single center } \\
\text { randomized } \\
\text { triple blind }\end{array}$ & yes & $\begin{array}{l}\text { PE post } \\
\text { heart } \\
\text { surgery }\end{array}$ & 149 & 57.4 & $\begin{array}{l}1 \mathrm{mc} \\
14 \mathrm{~d}\end{array}$ & $\begin{array}{l}\text { on p.o } 1 \text { for } \\
\text { ays }\end{array}$ & 0,5 & & $\begin{array}{l}\text { PPS } 1 \\
\text { months }\end{array}$ & yes \\
\hline 6 & $\begin{array}{l}\text { Inan et al. } \\
2011\end{array}$ & $\begin{array}{l}\text { Single center } \\
\text { randomized, } \\
\text { double blind }\end{array}$ & yes & $\begin{array}{l}\text { PE post } \\
\text { heart } \\
\text { surgery }\end{array}$ & 85 & $\begin{array}{l}50.3 \pm 8.3 \\
\exp \\
47.8 \pm 9.9 \\
\text { control }\end{array}$ & $\begin{array}{l}25 \mathrm{~m} \\
\text { begi } \\
\text { befo } \\
\text { six }\end{array}$ & $\begin{array}{l}\text { g x3 daily } \\
\text { ining } 7 \text { days } \\
\text { e surgery for } \\
\text { eeks p.o. }\end{array}$ & 1,5 & & PE 6 weeks & \\
\hline 7 & $\begin{array}{l}\text { Bunge et } \\
\text { al. }\end{array}$ & $\begin{array}{l}\text { Multicenter } \\
\text { randomizes } \\
\text { double blind }\end{array}$ & yes & $\begin{array}{l}\text { PPS } \\
\text { prevention }\end{array}$ & 822 & $\begin{array}{l}65 \pm 13.1 \\
\exp \\
64.7 \pm 12.7 \\
\text { control }\end{array}$ & $\begin{array}{l}1 \mathrm{mc} \\
\text { intra }\end{array}$ & $\begin{array}{l}\text { /kg single } \\
\text { sperative dose }\end{array}$ & Sing & e dose & 3 days & \\
\hline
\end{tabular}

Table 4

Jadad score.

\begin{tabular}{|lllllll|}
\hline Study number & Randomization & Randomization appropriate & Blinding & Blinding appropriate & Dropouts & Total score \\
\hline 1 & 1 & - & 1 & - & 1 & 3 \\
\hline 2 & 1 & 1 & 1 & 1 & 1 & 5 \\
\hline 4 & 1 & 1 & 1 & 1 & 5 \\
\hline 5 & 1 & 1 & 1 & 1 & 1 & 5 \\
\hline 6 & 1 & 1 & 1 & 1 & 1 & 5 \\
\hline 7 & 1 & 1 & 1 & 1 & 1 & 5 \\
\hline
\end{tabular}

Table 5

Univariate analysis performed to explore characteristics associated to potential reduction or increasing of events.

\begin{tabular}{|lllllc|}
\hline Events & Coefficient & Standard error & P value & \multicolumn{2}{c|}{ [95\% Confidence Interval] } \\
\hline Male & -4.317175 & 4.968603 & 0.545 & -67.44926 & 58.81491 \\
\hline Preoperative PE & 1.14948 & 1.09636 & 0.485 & -12.78109 & 15.08005 \\
\hline DM & -5.831674 & 6.330944 & 0.526 & -86.27395 & 74.6106 \\
\hline HTN & 3.163511 & 4.168874 & 0.587 & -49.80706 & 56.13408 \\
\hline CABG & 0.0086494 & 0.821112 & 0.993 & -3.52435 & 3.541649 \\
\hline Valvular procedure & -0.0173309 & 0.7954 & 0.985 & -3.439919 & 3.405317 \\
\hline
\end{tabular}


Table 6

Univariate analysis performed to explore characteristics associated to increasing of heterogeneity between the studies.

\begin{tabular}{|llllll|}
\hline Events & Coefficient & Standard error & \multicolumn{2}{c|}{ P value } & \multicolumn{2}{c|}{ [95\% Confidence Interval] } \\
\hline Age & -0.497029 & 0.8460575 & 0.557 & -2.155272 & 1.161213 \\
\hline Male & -0.519543 & 0.030505 & 0.089 & -0.111743 & 0.0078345 \\
\hline DM & -0.126203 & 0.0590587 & 0.033 & -0.2419561 & -0.0104503 \\
\hline HTN & -0.022957 & 0.0546208 & 0.674 & -0.1300122 & 0.0840976 \\
\hline Smoking & -0.034157 & 0.0470572 & 0.468 & -0.126388 & 0.0580728 \\
\hline Preoperative PE & 0.0163542 & 0.0072487 & 0.024 & 0.002147 & 0.03055615 \\
\hline CABG & -0.031086 & 0.0835963 & 0.710 & -0.1949327 & 0.1327589 \\
\hline Valvular procedure & 0.3062034 & 0.4554079 & 0.501 & -0.5863798 & 1.198787 \\
\hline Concomitant procedure & -0.411388 & 0.3536673 & 0.245 & -1.104563 & 0.2817868 \\
\hline
\end{tabular}

\section{Figures}

\begin{tabular}{|c|c|c|c|c|c|c|c|c|}
\hline \multirow[b]{2}{*}{ Study } & \multicolumn{2}{|c|}{ Treatment } & \multicolumn{2}{|c|}{ Control } & & & \multirow{2}{*}{$\begin{array}{l}\text { Log Odds-Ratio } \\
\text { with } 95 \% \mathrm{Cl}\end{array}$} & \multirow{2}{*}{$\begin{array}{l}\text { Weight } \\
(\%)\end{array}$} \\
\hline & Yes & No & Yes & No & & & & \\
\hline Study 1 & 5 & 42 & 14 & 50 & & $\longrightarrow$ & $-0.86\left[\begin{array}{ll}-1.96,0.25 \\
0\end{array}\right.$ & 11.19 \\
\hline Study 2 & 16 & 164 & 38 & 142 & & - & $-1.01[-1.63,-0.38]$ & 16.05 \\
\hline Study 3 & 35 & 145 & 53 & 127 & & & $-0.55[-1.04,-0.06]$ & 17.46 \\
\hline Study 4 & 25 & 73 & 33 & 66 & & 7 & $-0.38\left[\begin{array}{ll}-1.00, & 0.24\end{array}\right]$ & 16.14 \\
\hline Study 5 & 32 & 42 & 26 & 49 & & & $0.36\left[\begin{array}{ll}-0.30, & 1.02]\end{array}\right.$ & 15.66 \\
\hline Study 6 & 1 & 40 & 8 & 36 & & & $-2.18[-4.31,-0.06]$ & 5.03 \\
\hline Study 7 & 82 & 257 & 56 & 289 & & 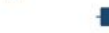 & $0.50[0.12,0.88]$ & 18.47 \\
\hline \multicolumn{5}{|c|}{ Overall } & & & $-0.38\left[\begin{array}{lll}-0.93, & 0.18\end{array}\right]$ & \\
\hline \multicolumn{9}{|c|}{ Heterogeneity: $\mathrm{I}^{2}=0.39, \mathrm{I}^{2}=79.27 \%, \mathrm{H}^{2}=4.82$} \\
\hline \multicolumn{9}{|c|}{ Test of $\theta=\theta ; Q(6)=28.94, p=0.00$} \\
\hline \multicolumn{9}{|c|}{ Test of $\theta=0: z=-1.34, p=0.18$} \\
\hline & & & & & -4 & -2 & 2 & \\
\hline
\end{tabular}

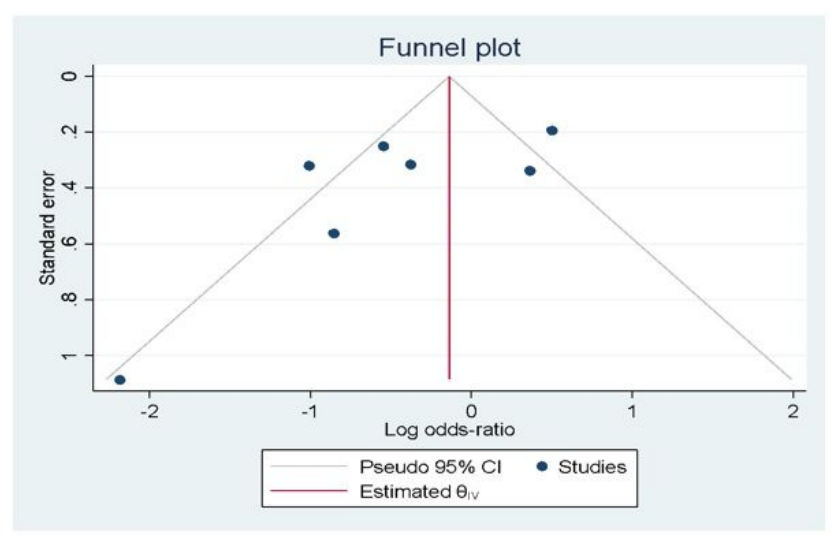

\section{Figure 1}

Forest Plot of Primary End-Point. Funnel Plot of Primary End-Point 


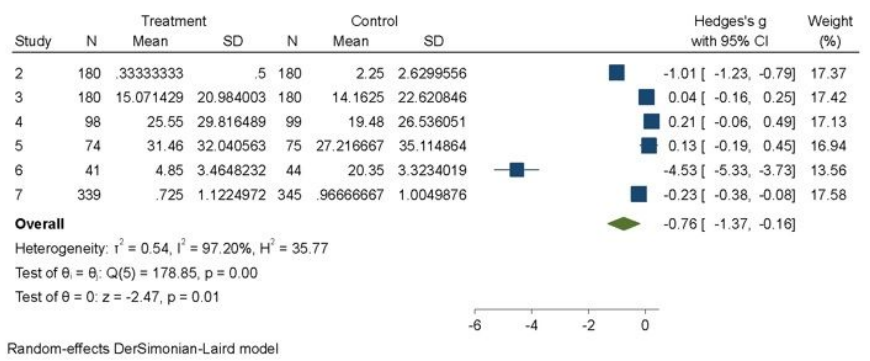

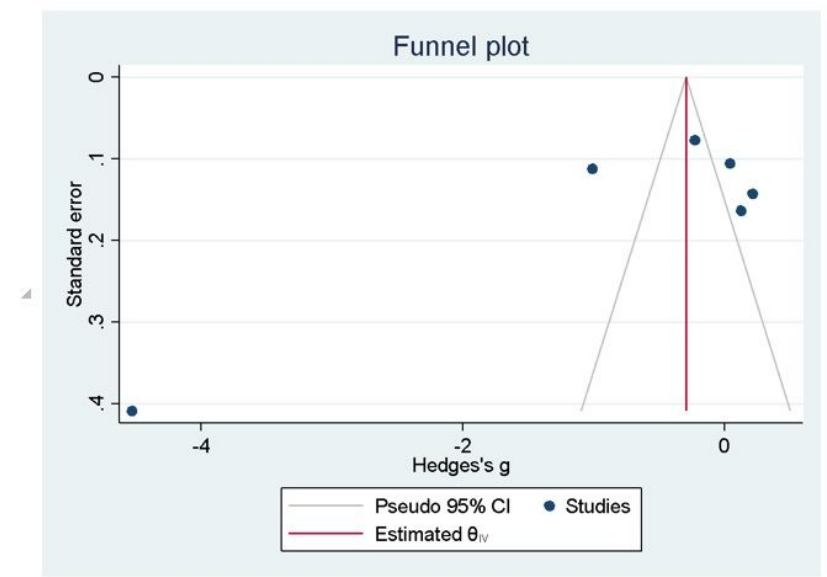

Figure 2

Forest Plot of Secondary End-Point. Funnel Plot of Secondary End-Point.

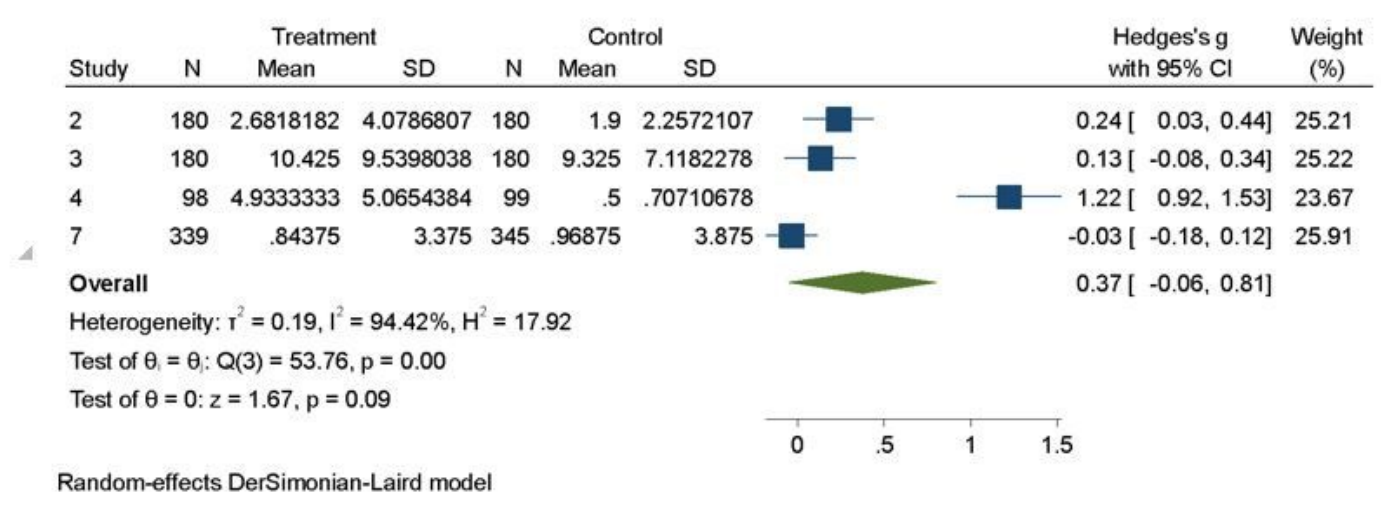

\section{Figure 3}

Forest Plot of Adverse effects. 